\title{
Blood Eosinophils in Chronic Obstructive Pulmonary Disease: Is There Enough Evidence?
}

\author{
Mario Cazzola, ${ }^{1}$ Maria Gabriella Matera $^{2}$ and Paola Rogliani ${ }^{1}$ \\ 1. Unit of Respiratory Medicine, Department of Experimental Medicine, University of Rome 'Tor Vergata', Rome, Italy; 2. Unit of Pharmacology, \\ Department of Experimental Medicine, University of Campania 'Luigi Vanvitelli', Naples, Italy
}

\section{Keywords}

Biomarker, blood count, COPD, Chronic Obstructive Pulmonary Disease, eosinophils, exacerbations, corticosteroids, inhalation therapy, pneumonia

Disclosures: Mario Cazzola, Maria Gabriella Matera and Paola Rogliani have no financial or non-financial relationships or activities to declare in relation to this article.

Review process: Double-blind peer review. Compliance with ethics: This article involves a review of the literature and did not involve any studies with human or animal subjects performed by any of the authors.

Authorship: The named authors meet the International Committee of Medical Journal Editors (ICMJE) criteria for authorship of this manuscript, take responsibility for the integrity of the work as a whole, and have given final approval for the version to be published.

Access: This article is freely accessible at touchRESPIRATORY.com. (c) Touch Medical Media 2021.

Received: 15 August 2020

Accepted: 10 January 202

Published online: 23 December 2021

Citation: touchREVIEWS in Respiratory \& Pulmonary Diseases. 2021;6(1):31-7

Corresponding author: Mario Cazzola, Dipartimento di Medicina Sperimentale, Università di Roma 'Tor Vergata', Via Montpellier 1, 00131 Rome, Italy. E: mario.cazzola@uniroma2.it

Support: No funding was received in the publication of this article.
The lack of well-validated biomarkers for monitoring disease activity, predicting future clinical outcomes and the effect of therapeutic interventions highlights the need to find new biomarkers in chronic obstructive pulmonary disease (COPD). In recent years, extensive research has gone into identifying and attempting to validate relevant diagnostic biomarkers of disease activity and therapeutic response.

A degree of eosinophil-associated airway inflammation can be present in both stable COPD and during acute exacerbations of COPD (AECOPDs); protection from AECOPDs with inhaled corticosteroids (ICSS) seems to be greatest in patients with higher blood eosinophil counts (BECS). Therefore, there has been increased interest in BECs as a biomarker for predicting the risk of AECOPDs and response to corticosteroid therapy. ${ }^{2.3}$ The 2020 Global Initiative for Chronic Obstructive Pulmonary Disease (GOLD) report recommends using BECs to guide treatment in patients with COPD in order to select the most appropriate patients for ICS therapy. ${ }^{4}$ For patients with one AECOPD per year, a peripheral blood level of $\geq 300$ eosinophils/ $\mu \mathrm{L}$ identifies those who are more likely to respond to long-acting $\beta_{2}$-agonists (LABA) or ICS treatment. For patients with two or more moderate exacerbations per year, or at least one severe exacerbation requiring hospitalization in the prior year, LABA/ICS treatment can be considered when BECS are $\geq 100$ cells/ $\mathrm{LL}$, as ICS effects are more pronounced in patients with greater AECOPD frequency and/or severity. In any case, a beneficial response after the addition of ICS may be observed when BECS are $\geq 100$ cells/ $\mu \mathrm{L}$, with a greater magnitude of response more likely with higher BECs.

In contrast to the GOLD report, the American Thoracic Society clinical practice guideline for the pharmacologic management of COPD is more pragmatic. It does not make recommendations for or against ICSS as an additive therapy to long-acting bronchodilators in patients with COPD and blood eosinophilia (defined as $\geq 2 \%$ blood eosinophils or $\geq 150$ cells $/ \mu \mathrm{L}$ ). However, the guideline does suggest ICSS as an additive therapy for patients with a history of one or more AECOPDs in the past year requiring antibiotics, oral steroids or hospitalization. This recommendation is conditional and means that treatment can be personalized for individual patients. Physicians must help each patient arrive at a management decision consistent with their values and preference.

There is strong support for the role of BECs as a biomarker in COPD; eosinophil measurement, plus clinical judgement and other patient-centred factors, have utility in developing individualized treatment plans for patients with COPD. ${ }^{6}$ However, the evidence showing a better response to ICSS with increased blood eosinophils comes from post hoc, secondary-prespecified and datamodelling analyses, which has generated many uncertainties that must be resolved before blood eosinophil levels can be endorsed to direct broad-based clinical therapy.7.8 Consequently, there is also concern regarding the real value of the BEC as a valid biomarker to predict AECOPD risk and the clinical response to ICSS. 
In this critical, narrative review, we examine the evidence that supports or denies a role for blood eosinophils in COPD, taking into consideration the strengths and the weaknesses of the material under review. The general aim of a data analysis in a critical review is to analyse and examine the literature and the main ideas and relationships of an issue. ${ }^{9}$ Systematic reviews are superior to critical reviews in answering specific questions. Over recent years we have conducted systematic reviews with sophisticated meta-analyses to answer specific questions, some of which will be resumed below. ${ }^{10}$ However, our aim is to provide a review of the most important and critical aspects of the current knowledge of the topic. We fully share the opinion that the interpretative elements of narrative reviews - which are better suited to addressing a topic in a wider way - are necessarily subjective and that the resulting product is the starting point for further evaluation and not an endpoint. ${ }^{11}$ The data analysis part of a critical review is not particularly developed according to a specific standard. ${ }^{12}$ We identified references through searches of PubMed using the keywords 'COPD' and 'blood eosinophils' up to August 2020. We supplemented the bibliographic database searches with backward citation tracking of relevant publications. The most significant information has been selected.

\section{Eosinophilic inflammation in chronic obstructive pulmonary disease}

COPD is conventionally considered a neutrophil-mediated inflammatory disease. ${ }^{13}$ However, eosinophils are present in the airways, tissues and blood of some patients with COPD, whether during stable disease or AECOPD. ${ }^{13-16}$ The lungs of patients with COPD contain more eosinophils than those of healthy subjects, but no more than $40 \%$ exhibit blood eosinophil levels $\geq 200$ cells/ $\mu \mathrm{L}$ and/or $\geq 2 \%{ }^{17,18}$

The role of eosinophils in COPD pathogenesis is still unclear, but is likely different from that in asthma and it is unknown why only some patients with COPD develop eosinophilic airway inflammation..$^{18}$ In patients with COPD and eosinophilia there is an increase in sputum interleukin (IL)-5 and an increase in the secretion of granulocyte-macrophage colony stimulating factor and CC chemokine ligand 5, which are central to maintaining eosinophil survival in lungs and to recruiting eosinophils, respectively, by airway epithelial cells. ${ }^{19}$ Additionally, epithelial cells of COPD patients secrete thymic stromal lymphopoietin (TSLP) and IL-33, which are important for the recruitment and activation of T helper-2 and type 2 innate lymphoid cells. ${ }^{19}$ There is documentation of a close association between aberrant TSLP signalling and COPD, and it has been suggested that TSLP expression by human airway smooth muscle cells may influence immune regulation by interacting with, and influencing local immune cells in, COPD airways. ${ }^{20}$ Multiple findings from several studies have connected eosinophilic inflammatory responses with excess localized expression of TSLP. ${ }^{21}$

Increasing evidence suggests that the presence of an eosinophilic inflammation in COPD is associated with severe AECOPD, longer hospital stays and higher risks of readmission; however, it has been highlighted that the association of high blood eosinophil levels and increased risk of AECOPDS is not strong. ${ }^{18,22}$ In a real-world COPD population study that used European data from the Adelphi Real World Respiratory Disease Specific Programme 2017 survey, more GOLD D patients had elevated BECs compared with GOLD B. ${ }^{23}$ The proportions of GOLD D patients with a history of $\geq 2$ exacerbations and BECs of $\geq 150, \geq 300$ and $\geq 400$ cells/ $\mu \mathrm{L}$ were $81.2 \%, 39.4 \%$ and $24.6 \%$, respectively. In total, $10.6 \%$ of patients had $\geq 300 \mathrm{cells} / \mathrm{\mu L}$ and a history of $\geq 2$ exacerbations.

We still do not know whether BEC predicts exacerbation risk independently of exacerbation phenotype, exacerbation treatment and what factors confound interpretation of the BEC. For example, infection may be particularly problematic because viral and bacterial infections can both increase and decrease BECs in patients with COPD. ${ }^{24}$ Nevertheless, an inverse relationship between bacterial counts and blood eosinophils was observed during AECOPDs but not in the stable state. Peripheral blood eosinophilia (defined as blood eosinophil levels of $\geq 2 \%$ ) must be considered a marker of non-infectious inflammatory exacerbations. ${ }^{25,26}$

\section{Peripheral blood eosinophils as a surrogate marker for sputum eosinophilia}

Performing differential cell counts and assessing mediator concentrations in induced sputum is a valid non-invasive technique for the assessment of airway inflammation. ${ }^{27}$ A significant increase in induced sputum eosinophils and eosinophil cationic protein levels was found in patients with stable COPD compared with healthy subjects. ${ }^{28} \mathrm{~A}$ high sputum eosinophil count is associated with a positive response to corticosteroid treatment in stable COPD; also it is useful to titrate corticosteroid therapy to reduce AECOPDS. ${ }^{15,29}$

However, there are some problems regarding the use of induced sputum. ' Sputum induction itself causes a local inflammatory response with transient, longer-lived eosinophilia, possibly due to local changes in osmolarity, activating epithelial and mast cells..$^{30}$ Furthermore, measuring sputum eosinophils is time consuming; some patients do not provide adequate samples because airflow obstruction that characterizes COPD cannot be totally prevented by premedication with a short-acting $\beta_{2}$-agonist (SABA) or an antimuscarinic agent, and sputum induction requires expertise and may not always be successful (the failure rate can be up to $30 \%)^{14,31}$

BECs have been used as a surrogate for eosinophilic airway inflammation because they are generally thought to be good predictors of eosinophil concentrations in the airways and measurements of BEC are more practical than performing eosinophil counts in induced sputum due to the ease of sample collection. ${ }^{32}$ Some studies have shown correlations between BECS and eosinophil counts in sputum, and a correlation between blood eosinophil percentages and eosinophil counts in bronchial submucosal samples. ${ }^{14,33,34}$

Apparently, eosinophilic inflammation in COPD emerges at lower levels than those that characterize eosinophilia (peripheral $\mathrm{BEC}>500 \mathrm{cells} / \mu \mathrm{L}) .{ }^{6}$ However, the threshold of BECs that defines the presence of pulmonary eosinophilic inflammation is still not clear. In fact, different thresholds, including relative values as a percentage of other cells present, of $\geq 2 \%$ or $\geq 4 \%$ or absolute values of $\geq 100, \geq 150$ or $\geq 300$ cells/ $\mu \mathrm{L}$ have been proposed, but it is difficult to recommend a single threshold because BECs vary during a 24-hour period in any subject. Also, BECs differ during stable disease, exacerbations and following treatment. ${ }^{32,35}$

\section{The reproducibility of blood eosinophil counts}

According to a US National Science Foundation subcommittee on replicability in science, "Reproducibility is a minimum necessary condition for a finding to be believable and informative" ${ }^{35}$ Reproducibility of results (previously described as replicability) refers to obtaining the same results from the conduct of an independent study whose procedures are closely matched; however, this is difficult to obtain when we analyse studies that have explored the role of blood eosinophils in COPD. ${ }^{36}$ The possibility of obtaining 'inferential reproducibility', which means drawing the same conclusions from either an independent replication of a study or a reanalysis of the original study, seems more realistic. However, there is 
a huge discrepancy between the available data, so obtaining inferential reproducibility is difficult. ${ }^{36}$

\section{The stability of blood eosinophil counts}

The stability and reproducibility of BEC over time is an issue that is relevant for its use as a biomarker in patients with COPD. Conceptually, the stability of BECs should reflect the eosinophilic count in the lung. However, blood eosinophils cannot be assumed to truly reflect lung tissue eosinophils, as documented by Turato et al., who were unable to find a correlation between tissue eosinophils from resected lung tissue and blood eosinophils in patients with COPD. ${ }^{37}$ Nevertheless, a recent study has documented that low levels of submucosal eosinophilic airway inflammation in patients with COPD are highly stable over time, whereas high levels show increased biological variability over time. ${ }^{38}$

An analysis of the COPDMAP observational cohort showed that approximately $70 \%$ of blood eosinophil measurements remained in the same category over 1 year using the GOLD 2019 thresholds $(<100$, $100-299$ or $\geq 300$ cells/ $/ \mathrm{L}$ ), and $85.3 \%$ of patients with eosinophils $<100$ cells/ $\mu \mathrm{L}$ had stable counts. ${ }^{39}$ Also, the analysis of the German COPD and Systemic Consequences-Comorbidities Network (COSYCONET) cohort demonstrated that in COPD, non-eosinophilia $(<150$ eosinophils/ $\mathrm{LL}$ ) in blood is more robust over time than eosinophilia defined as a count of $\geq 300$ cells $/ \mu \mathrm{L} .{ }^{40}$ When patients were stratified into persistently-low, variable and persistently-high blood eosinophil groups, no significant differences in baseline characteristics were detected among the groups. ${ }^{41}$

However, the repeatability of the peripheral BEC has been shown to be moderate. ${ }^{42} \mathrm{~A}$ population-based study that used data obtained from the Clinical Practice Research Datalink showed that the stability of peripheral BECS was significantly lower in patients with COPD compared with control subjects without COPD. ${ }^{43}$ In patients with COPD the stability was approximately $85 \%$ at 6 months and $62 \%$ at 2 years' follow-up, and declined progressively thereafter. In COPD, unstable eosinophilia was reported in as many as $40.5 \%$ (threshold $\geq 300$ cells $/ \mu \mathrm{L}$ ) to $49 \%$ (threshold $\geq 2 \%$ ) of the studied population. ${ }^{44,45}$ Consequently, a small proportion of patients remain with persistently elevated or lower BECS. Systemic corticosteroids, antibiotics, older age and male sex affect the stability of BECS, while the impact of ICS use or smoking status was negligible. ${ }^{18}$ Since BECs present significant variability throughout the course of COPD, it has been noted that a single measurement may not be a reliable predictor of future exacerbation risk and responsiveness of patients to ICSS. ${ }^{46}$

\section{Eosinophil levels and relation to outcomes in patients with chronic obstructive pulmonary disease}

Correlation between blood eosinophil levels and their consequences on COPD remains uncertain. Table 1 reports conflicting data on the value of BECs in influencing outcomes in COPD.

\section{Impact on lung function}

The Copenhagen General Population Study documented that individuals with $\mathrm{BECs} \geq 340$ cells $/ \mu \mathrm{L}$ had lower levels of forced expired volume in 1 second $\left(F E V_{1}\right)$ as a percentage of predicted value than individuals with COPD and low BECs. ${ }^{2}$ Furthermore, non-eosinophilic patients presented with higher post-bronchodilator $\mathrm{FEV}_{1}$ than patients with higher sputum eosinophils but not with higher blood eosinophils. ${ }^{47}$ However, in another study, FEV 1 reversibility seemed to be weakly correlated with sputum eosinophil levels in COPD. ${ }^{48}$
Rogliani et al. examined the time course of $\mathrm{FEV}_{1}$ over 4 years in patients with COPD who were allocated to two groups: either $<2 \%$ or $\geq 2 \%$ blood eosinophils. They observed an accelerated decline in the group with eosinophil levels $\geq 2 \%$ at baseline, while those with eosinophil levels $<2 \%$ had a significantly slower decline in $\mathrm{FEV}_{1}$ and a larger increase in forced vital capacity and residual volume. ${ }^{49}$ Conversely, the Hokkaido COPD Cohort Study Group investigators reported that in patients with COPD, lower BEC at baseline was associated with a rapid decline in $\mathrm{FEV}_{1}$ over a 10 -year period. ${ }^{50}$ However, an analysis of the UK Clinical Practice Research Datalink (primary care records) and Hospital Episode Statistics (hospital records) showed that the rate of $\mathrm{FEV}_{1}$ change was not significantly different when stratified by eosinophil level. ${ }^{51}$ Furthermore, data on two large cohorts of well-characterized patients with COPD showed that lung function tests were similar in patients irrespective of eosinophil level or longitudinal eosinophil level behaviour. ${ }^{44}$ It has been documented that peripheral eosinophil count is a poor reflection of lung function in patients with stable, steroidnaive, mild-to-moderate COPD. ${ }^{52}$

\section{Impact on exacerbations}

Several studies have suggested that higher blood eosinophil levels during stable disease may indicate a greater risk of exacerbation. The previously mentioned Copenhagen General Population study documented that in a general population context among individuals with COPD, blood eosinophil levels $>340$ cells $/ \mu \mathrm{L}$ were associated with an increased risk of moderate-to-severe exacerbations. ${ }^{2}$ Additionally, in patients with blood eosinophil levels $\geq 2 \%$, there was a higher rate of severe exacerbations. Furthermore, patients with moderate-to-severe COPD and BECS of $\geq 300$ cells $/ \mu \mathrm{L}$ had an increased risk of exacerbations in the COPDGene study, which was prospectively validated in the Evaluation of COPD to Longitudinally Identify Predictive Surrogate Endpoints (ECLIPSE) study (ClinicalTrials Identifier: NCT00292552), although this finding was observed only in patients with frequent exacerbations, but not in patients with 0 or 1 AECOPD in the previous year. ${ }^{53} \mathrm{~A}$ study that used a primary care electronic medical record database in Catalonia, Spain, showed that the number of exacerbations was slightly higher in patients with $<150 \mathrm{cell} / \mu \mathrm{L}$ or with $\geq 500 \mathrm{cell} / \mathrm{s} / \mathrm{l}$, and in those with higher variability in BECs.22

Conversely, persistent BECs $\geq 300$ cells/ $\mu \mathrm{L}$ over 2 years were not a risk factor for COPD exacerbations. ${ }^{45}$ In the Canadian Cohort Obstructive Lung Disease (CanCOLD) study (ClinicalTrials Identifier: NCT00920348), patients with blood eosinophil levels $>3 \%$ frequently reported at least one exacerbation in the previous year, and BECs $>300 \mathrm{cells} / \mu \mathrm{L}$ were associated with chronic phlegm..$^{54}$ In contrast, in patients with COPD and blood eosinophil levels $\geq 2 \%$ (regardless of the cut-off chosen) from the Initiatives BPCO French cohort, there was no difference in exacerbation rate. ${ }^{55}$ Also in the SPIROMICS database, BEC alone was not a reliable biomarker for COPD exacerbations. ${ }^{47}$

A retrospective cohort study from the UK Clinical Practice Research Datalink that included patients with COPD showed that it was the history of previous exacerbations that affected the appearance of further exacerbations regardless of the level of blood eosinophils. However, it was also noted that higher blood eosinophil levels were linked with a slightly increased incidence of moderate or severe exacerbations among those with a history of exacerbations. ${ }^{56}$ Intriguingly, a historical follow-up study that used longitudinal medical record data to evaluate BECS as a biomarker of exacerbation risk reported that elevated BECS might predict COPD exacerbation risk only in ex-smokers. ${ }^{57}$ 
Table 1: Conflicting data on the value of blood eosinophil counts in influencing outcomes in chronic obstructive pulmonary disease

\begin{tabular}{|c|c|c|}
\hline & Effect & Reference \\
\hline \multicolumn{3}{|c|}{ Impact on lung function } \\
\hline Pros & 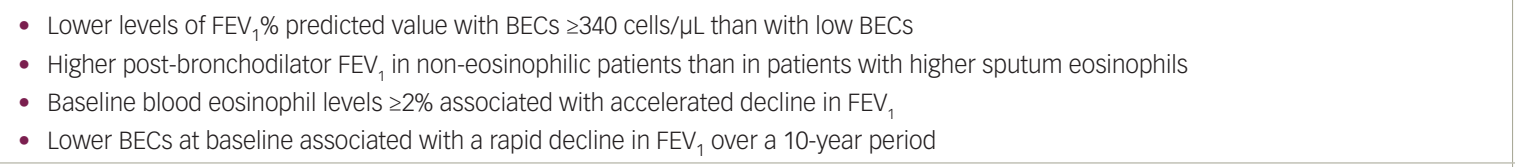 & $\begin{array}{l}2 \\
47 \\
49 \\
50\end{array}$ \\
\hline Cons & $\begin{array}{l}\text { - FEV } 1 \text { reversibility weakly correlated with sputum eosinophil levels } \\
\text { - Rate of FEV, change not significantly different when stratified by eosinophil level } \\
\text { - Lung function tests similar irrespective of eosinophil level or longitudinal eosinophil level behaviour }\end{array}$ & $\begin{array}{l}47 \\
51 \\
44\end{array}$ \\
\hline \multicolumn{3}{|c|}{ Impact on exacerbations } \\
\hline Pros & 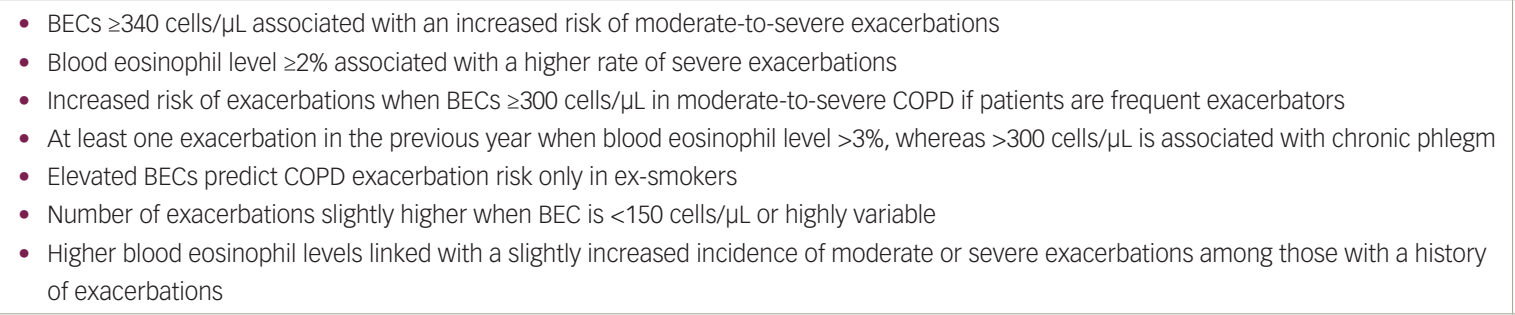 & $\begin{array}{l}2 \\
53 \\
54 \\
57 \\
22 \\
56\end{array}$ \\
\hline Cons & $\begin{array}{l}\text { - Persistent BECS } \geq 300 \text { cells/ } \mu \mathrm{L} \text { over } 2 \text { years not a risk factor for COPD exacerbations } \\
\text { - No difference in exacerbation rate with blood eosinophil levels } \geq 2 \% \text { (regardless the cut-off chosen) } \\
\text { - BEC alone is not a reliable biomarker for COPD severity or exacerbations } \\
\text { - The history of previous exacerbations affects the appearance of further exacerbations regardless of blood eosinophil levels }\end{array}$ & $\begin{array}{l}45 \\
55 \\
47 \\
56\end{array}$ \\
\hline \multicolumn{3}{|c|}{ Impact on quality of life } \\
\hline Pros & 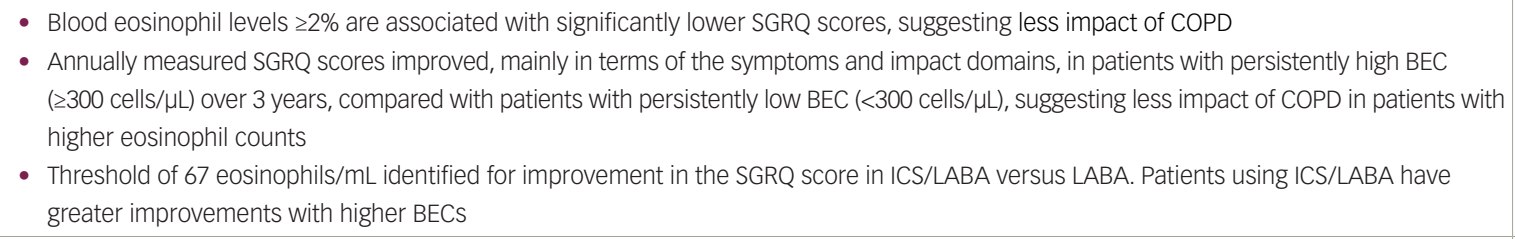 & $\begin{array}{l}45,55 \\
41 \\
58\end{array}$ \\
\hline \multicolumn{3}{|c|}{ Impact on survival } \\
\hline Pros & $\begin{array}{l}\text { - Significantly lower risk of death associated with persistently elevated BECs ( } \geq 300 \text { cells } / \mu \mathrm{L} \text { ) over } 2 \text { years } \\
\text { - Improved overall survival in patients with a BEC } \geq 300 \text { cells/ } \mu \mathrm{L} \text { compared with those with a BEC }<300 \text { cells/ } \mu \mathrm{L} \\
\text { - Survival period increases with increasing BEC }\end{array}$ & $\begin{array}{l}44 \\
61 \\
60\end{array}$ \\
\hline Cons & $\begin{array}{l}\text { - No significant association with all-cause mortality among patients with COPD and absolute BECs } \geq 340 \text { cells } / \mu \mathrm{L} \text { versus }<340 \text { cells/ } \mu \mathrm{L} \\
\text { - No difference in the risk of on-treatment deaths in patients with COPD regardless of treatment using a blood eosinophil cut-off of }<2 \% \\
\text { versus } \geq 2 \% \text { to categorize patients } \\
\text { - Elevated BECs ( } \geq 200 \text { cells } / \mu \mathrm{L} \text { ) not associated with mortality when compared with patients with COPD and decreased BECs }\end{array}$ & $\begin{array}{l}62 \\
3 \\
63\end{array}$ \\
\hline \multicolumn{3}{|c|}{ Impact on incidence of pneumonia } \\
\hline Pros & $\begin{array}{l}\text { - More pneumonia events in patients with COPD with eosinophil levels }<2 \% \text { than in those with higher counts } \\
\text { - Only in severe } \mathrm{COPD} \text { ( } \mathrm{FEV}_{1}<50 \% \text { predicted), BECs } \geq 340 \text { cells/ } \mu \mathrm{L} \text { associated with high risk of hospitalization due to pneumonia. With } \mathrm{FEV} \\
\geq 50 \% \text { predicted, trend toward significant decrease in the risk of pneumonia }\end{array}$ & $\begin{array}{l}64 \\
66\end{array}$ \\
\hline Cons & - Differences in risk of pneumonia according to BECs not observed in retrospective re-analyses of clinical trials & 58,67 \\
\hline
\end{tabular}

$B E C=$ blood eosinophil count; $C O P D=$ chronic obstructive pulmonary disease; $F E V_{1}=$ forced expired volume in one second; ICS = inhaled corticosteroid; $L A B A=$ Iong-acting $\beta_{2}-$ agonist; SGRQ = St George Respiratory Questionnaire.

\section{Impact on quality of life}

Some studies have shown that patients with COPD and higher eosinophil levels $(\geq 2 \%)$ have significantly lower St George Respiratory Questionnaire (SGRQ) scores. ${ }^{45,55}$ Furthermore, annually measured SGRQ scores improved in patients with persistently high BECs ( $\geq 300$ cells/ $\mu \mathrm{L})$ over 3 years compared with patients with persistently low BECS ( $<300$ cells/ML), mainly in terms of symptoms and impact domains. ${ }^{41}$ These findings suggest a lower impact of COPD in patients with higher eosinophil counts.
In the retrospective re-analysis of the Foster 48-Week Trial to Reduce Exacerbations in COPD (FORWARD) (ClinicalTrials Identifier: NCT00929851) study that compared 48 weeks of treatment with ICS/LABA (extrafine beclomethasone dipropionate plus formoterol fumarate) versus LABA alone (formoterol fumarate), a threshold for improvement in the SGRQ score of 67 eosinophils/ $\mu \mathrm{L}$ was identified and patients using ICS/LABA had greater improvements with higher BECS.58 This finding contrasts with the results of re-analysed data from three randomized controlled trials of at least 1-year duration comparing ICS or ICS/LABA combination therapy 
(with a long-acting muscarinic antagonist [LAMA]), LABA or placebo according to baseline eosinophil categories (baseline blood eosinophil level $<2 \%$ and $\geq 2 \%$ ). These data found no treatment differences for fluticasone propionate/salmeterol versus any comparator in change from baseline SGRQ score in either of the eosinophil subgroups. ${ }^{59}$

\section{Impact on survival}

A significantly lower risk of death has been reported in patients with persistently elevated eosinophils over 2 years than in those whose levels were lower than the predetermined threshold of $300 \mathrm{cells} / \mu \mathrm{LL}{ }^{44}$ Utilizing data from the specialty care hospital register of the Hospital District of Southwest Finland, it was found that patients with a BEC $\geq 300$ cells/ $\mathrm{LL}$ had improved overall survival compared with those with a $\mathrm{BEC}<300$ cells $/ \mu \mathrm{L} .{ }^{60}$ In particular, an analysis of two different prospective COPD cohort studies in South Korea showed that survival period increased with increasing BEC.61

In contrast, there was no significant association with all-cause mortality among patients with COPD with absolute BECs $\geq 340$ cells/ $\mu \mathrm{L}$ versus $<340$ cells/ $\mu \mathrm{L}$ in a cohort study conducted using the UK Clinical Practice Research Datalink. ${ }^{62}$ Furthermore, a retrospective analysis of data from the ISOLDE study, using blood eosinophil cut-offs of $<2 \%$ versus $\geq 2 \%$ to categorize patients, found no difference in the risk of on-treatment deaths in patients with COPD regardless of treatment in both eosinophil groups. Elevated BECs ( $\geq 200$ cells $/ \mu \mathrm{L}$ ) were not associated with mortality when compared with patients with COPD with decreased BECs.,63

\section{Impact on incidence of pneumonia}

The correlation between reduced eosinophil levels and the incidence of pneumonia remains uncertain. Pavord et al. examined patient-level data from the GlaxoSmithKline clinical trial registry, and observed that patients with COPD with eosinophil levels $<2 \%$ had more pneumonia events than did those with higher counts. ${ }^{64}$ This finding fits well with the documentation that higher sputum eosinophil levels are associated with less bacterial colonization in the stable state and that low BECs $(<100$ cells/ $\mathrm{LL}$ ) are associated with increased risks of chronic bacterial infection and pneumonia. ${ }^{25,65}$

Conversely, data from the Copenhagen General Population Study showed that in patients with severe COPD ( $\mathrm{FEV}_{1}<50 \%$ predicted), $\mathrm{BEC} \geq 340$ cells $/ \mu \mathrm{L}$ was associated with high risk of hospitalization due to pneumonia. ${ }^{66}$ However, in patients with $\mathrm{FEV}_{1} \geq 50 \%$ predicted and blood eosinophilia, there was a trend toward significance in diminishing the risk of pneumonia. Differences in risk of pneumonia according to BECs were not observed in other retrospective reanalyses of clinical trials. ${ }^{58,67}$

\section{Blood eosinophil counts as predictors of response to inhaled corticosteroids}

A number of post hoc analyses and meta-analyses of randomized controlled trials have demonstrated a link between higher BECS and ICS effects on AECOPD prevention. ${ }^{6}$ However, it has been highlighted that in many studies where blood eosinophils were determined to predict ICS effect, a history of asthma was not systematically excluded. ${ }^{68}$

Nevertheless, Bafadehl et al. found that the effect of ICS/LABA treatment compared to LABA monotherapy on exacerbation prevention was observed at above approximately 100 eosinophils/ $\mu \mathrm{L}$ at the start of the study, with increasingly larger benefits at higher BECs. ${ }^{69}$ Furthermore, they reported a linear relationship between $\mathrm{BEC}$ and $\mathrm{FEV}$, and SGRQ total score with LABA/ICS treatment; the minimum clinically important difference in treatment effect compared with LABA alone occurred at a BEC of 270 cells/ $\mu \mathrm{L}$ for $F E V_{1}$ and 480 cells/ $\mu \mathrm{L}$ for SGRQ total score.

Another post-hoc analysis showed that LABA/ICS treatment offers protective effects for clinically important deteriorations, a composite endpoint consisting of three components of COPD worsening (AECOPDS, deteriorations in $\mathrm{FEV}_{1}$ and increases in SGRQ total score), compared with LABA alone, with the magnitude of the effect dependent on patients' eosinophil levels. ${ }^{70}$ In patients with low BECS $(<100$ cells/ $\mu \mathrm{L})$, the treatment benefit of LABA/ICS versus LABA, and thus the effect of ICS, was poor to minimal. It has also been documented that the protective effect of ICS/LABA/LAMA combination therapy versus LABA/LAMA combination therapy for the risk of moderate or severe AECOPD was greater in patients with higher BECs, but no significant effect modifiers were found for trough $\mathrm{FEV}_{1}{ }^{71}$

A meta-analysis of five studies comprising 12,496 patients with moderate-to-very severe COPD suggested not only a modest benefit from ICS-containing treatments versus non-ICS, ICS withdrawal or placebo in reducing the annual rate of moderate/severe exacerbations, but also an increase in the incidence of pneumonia risk in patients with COPD with blood eosinophil levels $\geq 2 \%$ at baseline. ${ }^{72}$

More detailed information was generated by a post hoc analysis of the Withdrawal of Inhaled Steroids during Optimized Bronchodilator Management (WISDOM) trial (ClinicalTrials Identifier: NCT00975195), suggesting that a significant increase in the annual exacerbation rate for patients in the ICS-withdrawal group versus the ICS-continuation group can be only observed when the baseline BEC is $\geq 300$ cells $/ \mu \mathrm{L}$ or $\geq 4 \%{ }^{73}$ ICS withdrawal in patients with COPD with BECS $\geq 300$ cells/HL was associated with a higher exacerbation risk particularly in patients with a history of at least two exacerbations per year. ${ }^{74}$ However, in the Effect of Indacaterol Glycopyrronium versus Fluticasone Salmeterol on COPD Exacerbations (FLAME) study (ClinicalTrials Identifier: NCT01782326), the annual rate of exacerbations was lower with LABA/LAMA versus LABA/ ICS, independent of the baseline eosinophil level $(<2 \% \text { versus } \geq 2 \%)^{75}$ Prespecified analyses of data from this study did not show a significant difference in the rate of AECOPDs between the LABA/LAMA and LABA/ ICS groups at higher baseline eosinophil thresholds (i.e. $\geq 3 \%$, $\geq 5 \%$ or $\geq 300$ cells $/ \mu \mathrm{L}) .{ }^{76}$ Furthermore, a real-world primary care population, in which continuous ICS users and those who had withdrawn ICSs were stratified by absolute ( 340 cells/ $\mu \mathrm{L}$ as a cut-off value) or relative ( $4 \%$ as a cut-off value) BECS, did not show an increased risk of moderate and/or severe AECOPDs or all-cause mortality among patients with blood eosinophilia who withdrew their use of ICS. ${ }^{62}$

A substantial difference was observed when comparing the data generated by randomized controlled trials with those of the observational studies. In fact, a systematic review of post hoc analyses of 11 randomized controlled trials and 5 observational studies that examined the association between three blood eosinophil thresholds (a relative eosinophil count of $2 \%$ and absolute counts of $150 \mathrm{cells} / \mathrm{\mu L}$ and $300 \mathrm{cell} / \mathrm{SL}$ ) and the response of exacerbation risk to ICSS in patients with COPD found that the independent effect of ICSS on the reduction of exacerbation risk was $20 \%$ at $\geq 2 \%$ BEC threshold, $35 \%$ at $\geq 150$ cells/ $\mu \mathrm{L}$ BEC threshold, and $39 \%$ at $\geq 300$ cells/ $\mu \mathrm{L}$ BEC threshold. ${ }^{77}$ However, no association was found in four out of five observational studies. It has been highlighted that almost all data reporting an association between BEC levels and AECOPDS or ICS response come from patients enrolled in randomized controlled trials enriched for a prior history of frequent or severe exacerbation. ${ }^{51}$ 
In a large British primary care cohort of patients with COPD, prevalent ICS use was associated with slower rates of $\mathrm{FEV}_{1}$ decline in COPD regardless of blood eosinophil level. ${ }^{78}$ Another study, that stratified ISC users and non-users with COPD into two groups based on baseline eosinophil levels ( $\geq 2 \%$ and $<2 \%$ ), found that response to bronchodilators, in terms of trough $\mathrm{FEV}_{1}$, dyspnoea and health-related quality of life, was similar in both groups. ${ }^{67}$

Asalreadymentioned, blood eosinophil levels presentsignificantvariability throughout the course of COPD; therefore, a single measurement may not be a reliable predictor of ICS response considering that corticosteroids are able to suppress eosinophils, at least in the sputum of patients with COPD. ${ }^{15,46}$ However, an analysis of the data from the InforMing the Pathway of COPD Treatment (IMPACT) trial (ClinicalTrials Identifier: NCT02164513) suggested that two blood eosinophil measurements do not appear to provide additional information to predict ICS response in COPD versus one value. ${ }^{79}$

A post hoc analysis of the Inhaled Steroids in Obstructive Lung Disease in Europe (ISOLDE) study has recently shown that in eosinophil suppression of $\geq 200$ cells $/ \mu \mathrm{L}$, ICS use was associated with a decelerated FEV ${ }_{1}$ decline rate by $32 \mathrm{~mL} / \mathrm{year}$, and a 30\% reduction in the exacerbation rate. In contrast, in patients experiencing an increase in eosinophils of $\geq 200$ cells/ $/ \mathrm{L}$, ICS use was associated with an accelerated $\mathrm{FEV}_{1}$ decline rate by $37 \mathrm{~mL} /$ year and an increased exacerbation rate by $80 \% .^{80}$ Eosinophil change was not predictive of clinical response with regard to health status evaluated using SGRQ.

\section{Conclusion}

Although there is increasing pressure for the use of BEC in COPD (justified by some interesting information) we agree that the evidence supporting BEC as a biomarker in patients with COPD is still too weak. ${ }^{35,81,82}$ In fact, not only is the literature rich in contrasting data, but there are still fundamental points that need to be clarified before we can make sound judgement.

The pooled analysis of the Benralizumab Efficacy in Moderate to Very Severe Chronic Obstructive Pulmonary Disease with Exacerbation History (GALATHEA; ClinicalTrials Identifier: NCT02138916) and Efficacy and Safety of Benralizumab in Moderate to very Severe Chronic Obstructive Pulmonary Disease with Exacerbation History (TERRANOVA; ClinicalTrials Identifier: NCT02155660) phase III trials was designed to evaluate the efficacy and safety of benralizumab (which targets IL-5 receptor $\alpha$ and depletes eosinophils through antibody-dependent cellular cytotoxicity) for patients with moderate-to-very severe COPD. In patients with eosinophilic inflammation (BECs $\geq 220$ cells/ $\mu \mathrm{L}$ ) and an increased risk of AECOPDs it was shown that elevated BEC alone was insufficient to identify treatment effect with anti-eosinophil therapy. ${ }^{83}$ In fact, not only when coupled mainly with three or more AECOPDS in the previous year, but also with post-bronchodilator $\mathrm{FEV}_{1}<40 \%$ of predicted normal, or post-bronchodilator response to SABAs of $\geq 15 \%$, the baseline elevated blood eosinophils were strong predictors of treatment effect for AECOPD rate reduction with benralizumab.

The finding that eosinophil depletion has a minimal effect on AECOPD rate suggests that eosinophil depletion is unlikely to ameliorate exacerbation outcomes for the majority of patients with COPD. Furthermore, the effect of corticosteroids may not be not related to the decrease in eosinophils in the blood, but rather to their multiple actions in the most severe forms of COPD when combined with a LABA ${ }^{84}$ According to Miravitlles et al., blood eosinophils may be a reasonable predictor of risk only in patients with COPD who have frequent exacerbations; however, as already mentioned, there was a marked difference in the incidence rate of AECOPD in those with previous AECOPD compared with those with no such history, regardless of eosinophil levels.22,56 Nevertheless, the evidence generated by the re-analysis of the ISOLDE results by baseline BEC, supporting the possible efficacy of ICSS in susceptible patients in whom the eosinophil count decreased after the oral corticosteroids, complicates matters further. ${ }^{3}$

Unfortunately, we have not yet understood whether eosinophils are causally related in the pathogenesis of a patient's AECOPD risk or whether it is just an epimarker of other biological processes that predispose patients to increased exacerbation risk. However, this latter hypothesis contrasts with the documentation that in patients with significant emphysema in high-resolution computed tomography there were lower blood eosinophil levels, and these differences were present irrespective of frequent exacerbation history or the use of ICSS.8.85

It is likely that the substantial contrast between randomized controlled trial data and real-world studies adds to the uncertainty regarding the value of BEC as a biomarker in COPD. A recent study examined the association between blood eosinophil levels and the subsequent rate of AECOPDS in a population-based cohort of patients with COPD managed in primary care. The study reported that a history of AECOPD and ICS use appeared to be associated with the impact of blood eosinophil levels on the rate of AECOPD. ${ }^{86}$ In particular, this study suggests that ICS use may diminish the association between blood eosinophil levels and AECOPD risk, and undermines the importance of ICS-containing therapies in patients with high blood eosinophil levels. It is well known that a large percentage of patients are still inappropriately prescribed ICSS for the management of COPD; therefore, it cannot be excluded that this incongruous use may cause the eosinophil value to differ from that found in randomized controlled trials in which there is tight control over treatments and the outcome measures are collected prospectively and carefully. ${ }^{87}$

Nonetheless, although there is a seemingly well-established conviction that studies have firmly supported BECs as a prognostic biomarker and a predictor of response to ICSS, we believe that the use of blood eosinophil level as a valuable biomarker to guide COPD treatment in clinical practice, remains largely unsupported. ${ }^{81,88} \square$
1. Cazzola M, Novelli G. Biomarkers in COPD. Pulm Pharmacol Ther. 2010;23:493-500.

2. Vedel-Krogh S, Nielsen SF, Lange P, et al. Blood eosinophils and exacerbations in chronic obstructive pulmonary disease. The Copenhagen general population study. Am J Respir Crit Care Med. 2016;193:965-74.

3. Barnes NC, Sharma R, Lettis S, Calverley PM. Blood eosinophils as a marker of response to inhaled corticosteroids in COPD. Eur Respir J. 2016;47:1374-82.

4. The Global Initiative for Chronic Obstructive Lung Disease (GOLD). 2020. Available at: https://goldcopd.org/ (accessed 14 July 2020)

5. Nici L, Mammen MJ, Charbek E, et al. Pharmacologic management of chronic obstructive pulmonary disease. An Official American Thoracic Society Clinical Practice Guideline.
Am J Respir Crit Care Med. 2020;201:e56-69.

6. Wade RC, Wells JM. POINT: are eosinophils useful for the management of COPD? Yes. Chest. 2020;157:1073-5. 7. Lopez-Campos JL, Carrasco-Hernandez L, Quintana-Gallego E, et al. Triple therapy for COPD: a crude analysis from a systematic review of the evidence. Ther Adv Respir Dis. 2019:13:1753466619885522.

8. Criner GJ. COUNTERPOINT: are eosinophils useful for the management of COPD? No. Chest. 2020;157:1075-8.

9. Snyder H. Literature review as a research methodology: an overview and guidelines. J Bus Res. 2019:104:333-9.

10. Franco JVA, Arancibia M, Simancas-Racines D, Madrid E. Franco JVA, Arancibia M, Simancas-Racines D, Madrid E.
Syntheses of biomedical information: narrative reviews, systematic reviews and emerging formats. Medwave. 2018;18:e7354
11. Grant MJ, Booth A. A typology of reviews: an analysis of 14 review types and associated methodologies. Health Info Libr J. 2009;26:91-108.

12. Whittemore R, Knafl $K$. The integrative review: updated methodology. J Adv Nurs. 2005;52:546-53.

13. Barnes PJ. Immunology of asthma and chronic obstructive pulmonary disease. Nat Rev Immunol. 2008;8:183-92.

14. Negewo NA, MCDonald VM, Baines KJ, et al. Peripheral blood eosinophils: a surrogate marker for airway eosinophilia in eosinophils: a surrogate marker for airway eosinophilia in
stable COPD. Int I Chron Obstruct Pulmon Dis. 2016;11:1495504.

15. Siva R, Green RH, Brightling CE, et al. Eosinophilic airway inflammation and exacerbations of COPD: a randomised controlled trial. Eur Respir J. 2007;29:906-13.

16. Jabarkhil A, Moberg M, Janner J, et al. Elevated blood 
eosinophils in acute COPD exacerbations: better short- and long-term prognosis. Eur Clin Respir J. 2020;7:1757274.

17. Rutgers SR, Timens $W$, Kaufmann HF, et al. Comparison of induced sputum with bronchial wash, bronchoalveolar lavage and bronchial biopsies in COPD. Eur Respir 」. 2000:15:109-15.

18. Mycroft K, Krenke R, Górska K. Eosinophils in COPD - Current concepts and clinical implications. J Allergy Clin Immunol Pract. 2020;8:2565-74.

19. Barnes PJ. Inflammatory endotypes in COPD. Allergy. 2019;74:1249-56.

20. Redhu NS, Gounni AS. Function and mechanisms of TSLP/ TSLPR complex in asthma and COPD. Clin Exp Allergy. 2012;42:994-1005

21. Smith DE, Comeau MR. Chapter 16.5. Regulation of eosinophil responses by the epithelial-derived cytokines TSLP, IL-25, and IL-33. In: Lee JJ and Rosenberg HF (eds). Eosinophils in Health and Disease. Cambridge, MA, USA: Academic Press, 2012;641-3.

22. Miravitlles M, Monteagudo M, Solntseva I, Alcázar B. Blood eosinophil counts and their variability and risk of exacerbation in COPD: a population-based study. Arch Bronconeumol. 2021:57:13-20.

23. Vestbo J, Vogelmeier $\mathrm{CF}$, Small M, et al. Inhaled corticosteroid use by exacerbations and eosinophils: a real-world COPD population. Int J Chron Obstruct Pulmon Dis. 2019;14:853-61.

24. Brusselle G, Pavord ID, Landis S, et al. Blood eosinophil levels as a biomarker in COPD. Respir Med. 2018;138:21-31.

25. Kolsum U, Donaldson GC, Singh R, et al. Blood and sputum eosinophils in COPD; relationship with bacterial load. Respir Res. 2017;18:88.

26. Alcázar Navarrete B, Ancochea Bermúdez J, García-Río F, et al. Patients with chronic obstructive pulmonary disease exacerbations: recommendations for diagnosis. Arch Bronconeumol. 2019:55:478-87.

27. Pavord ID, Sterk PJ, Hargreave FE, et al. Clinical applications of assessment of airway inflammation using induced sputum. Eur Respir J Suppl. 2002;37:40s-3s.

28. Balzano $\mathrm{G}$, Stefanelli $\mathrm{F}$, Iorio $\mathrm{C}$, et al. Eosinophilic inflammation in stable chronic obstructive pulmonary disease. Relationship with neutrophils and airway function. Am J Respir Crit Care Med. 1999;160(5 Pt 1):1486-92.

29. Brightling CE, MCKenna S, Hargadon B, et al. Sputum eosinophilia and the short-term response to inhaled mometasone in chronic obstructive pulmonary disease. Thorax. 2005;60:193-8.

30. van der Vaart H, Postma DS, Timens W, et al. Repeated sputum inductions induce a transient neutrophilic and eosinophilic response. Chest. 2006;130:1157-64.

31. Wilson AM, Leigh R, Hargreave FE, et al. Safety of sputum induction in moderate-to-severe smoking-related chronic obstructive pulmonary disease. COPD. 2006;3:89-93.

32. Tashkin DP, Wechsler ME. Role of eosinophils in airway inflammation of chronic obstructive pulmonary disease. Int J Chron Obstruct Pulmon Dis. 2018;13:335-49.

33. Bafdhel M, McKenna S, Terry S, et al. Acute exacerbations of chronic obstructive pulmonary disease: identification of biologic clusters and their biomarkers. Am J Respir Crit Care Med. 2011;184:662-71.

34. Eltboli O, Mistry V, Barker B, Brightling CE. Relationship between blood and bronchial submucosal eosinophilia and reticular basement membrane thickening in chronic obstructive pulmonary disease. Respirology. 2015;20:667-70.

35. Oliver B, Tonga K, Darley D, et al. COPD treatment choices based on blood eosinophils: are we there yet? Breathe (Sheff). 2019;15:318-23.

36. Bollen K, Cacioppo JT, Kaplan R, et al. Social, behavioral, and economic sciences perspectives on robust and reliable science (National Science Foundation, Arlington, VA, 2015). Available at: www.nsf.gov/sbe/AC_Materials/SBE_Robust_and_Reliable Research_Report.pdf (accessed 16 July 2020).

37. Turato G, Semenzato U, Bazzan E, et al. Blood eosinophilia neither reflects tissue eosinophils nor worsens clinical outcomes in chronic obstructive pulmonary disease. Am Respir Crit Care Med. 2018;197:1216-9.

38. Higham A, Leow-Dyke S, Jackson N, Singh D. Stability of eosinophilic inflammation in COPD bronchial biopsies. Eur Respir J. 2020;56:2000622.

39. Long GH, Southworth T, Kolsum U, et al. The stability of blood eosinophils in chronic obstructive pulmonary disease Respir Res. 2020;21:15.

40. Greulich T, Mager S, Lucke T, et al. Longitudinal stability of blood eosinophil count strata in the COPD COSYCONET cohort. Int Chron Obstruct Pulmon Dis. 2018:13:2999-3002.

41. Shin SH, Park HY, Kang D, et al. Serial blood eosinophils and clinical outcome in patients with chronic obstructive pulmonary disease. Respir Res. 2018;19:134.

42. Bafadhel M, Pavord ID, Russell REK. Eosinophils in COPD: just another biomarker? Lancet Respir Med. 2017;5:747-59.

43. Oshagbemi OA, Burden AM, Braeken DCW, et al Stability of blood eosinophils in patients with chronic obstructive pulmonary disease and in control subjects, and the impact of sex, age, smoking, and baseline counts. Am J Respir Crit Care Med. 2017;195:1402-4

44. Casanova C, Celli BR, de-Torres JP, et al. Prevalence of persistent blood eosinophilia: relation to outcomes in patients with COPD. Eur Respir J. 2017;50:1701162.

45. Singh D, Kolsum U, Brightling CE, et al. Eosinophilic inflammation in COPD: prevalence and clinical characteristics. Eur Respir J. 2014;44:1697-700.

46. Schumann DM, Tamm M, Kostikas K, Stolz D. Stability of the blood eosinophilic phenotype in stable and exacerbated COPD. Chest. 2019;156:456-65.

47. Hastie AT, Martinez FJ, Curtis JL, et al. Association of sputum and blood eosinophil concentrations with clinical measures of COPD severity: an analysis of the SPIROMICS cohort. Lancet Respir Med. 2017;5:956-67.

48. Chou KT, Su KC, Hsiao YH, et al. Post-bronchodilator reversibility of FEV1 and eosinophilic airway inflammation in COPD. Arch Bronconeumol. 2017;53:547-53

49. Rogliani P, Puxeddu E, Ciaprini C, et al. The time course of pulmonary function tests in COPD patients with different levels of blood eosinophils. Biomed Res Int. 2016;2016:4547953.

50. Suzuki M, Makita H, Konno S, et al. Annual change in FEV1 in elderly 10-year survivors with established chronic obstructive pulmonary disease. Sci Rep. 2019;9:2073.

51. Whittaker HR, Müllerova $H$, Jarvis $D$, et al. Inhaled corticosteroids, blood eosinophils, and FEV1 decline in patients with COPD in a large UK primary health care setting. Int I Chron Obstruct Pulmon Dis. 2019:14:1063-73.

52. Proboszcz M, Mycroft K, Paplinska-Goryca M, et al. Relationship between blood and induced sputum eosinophils, bronchia hyperresponsiveness and reversibility of airway obstruction in mild-to-moderate chronic obstructive pulmonary disease. COPD. 2019;16:354-61

53. Yun JH, Lamb A, Chase R, et al. Blood eosinophil count thresholds and exacerbations in patients with chronic obstructive pulmonary disease. J Allergy Clin Immuno. 2018;141:2037-47.

54. Tan WC, Yau T, Bourbeau J, et al. The association between blood eosinophils counts and clinical characteristics in individuals with COPD: preliminary findings from the populationbased CancolD study Abstr. Am I Respir Crit Care Med. 2018;197:A7508.

55. Zysman M, Deslee G, Caillaud D, et al. Relationship between blood eosinophils, clinical characteristics, and mortality in patients with COPD. Int $J$ Chron Obstruct Pulmon Dis. 2017:12:1819-24.

56. Landis SH, Pimenta JM, Yang S, et al. Association between blood eosinophils and acute exacerbation of COPD risk in patients with COPD in primary care. Respir Med X. 2019;1:100011.

57. Kerkhof M, Sonnappa S, Postma DS, et al. Blood eosinophil count and exacerbation risk in patients with COPD. Eur Respir J. 2017:50:1700761

58. Siddiqui SH, Pavord ID, Barnes NC, et al. Blood eosinophils: a biomarker of COPD exacerbation reduction with inhaled corticosteroids. Int J Chron Obstruct Pulmon Dis. 2018:13:3669-76.

59. Pavord ID, Lettis S, Locantore $\mathrm{N}$, et al. Blood eosinophils and inhaled corticosteroid/long-acting $\beta$-2 agonist efficacy in COPD. Thorax. 2016;71:118-25.

60. Viinanen A, Lassenius MI, Toppila I, et al. The burden of chronic obstructive pulmonary disease (COPD) in Finland: impact of disease severity and eosinophil count on healthcare resource utilization. Int J Chron Obstruct Pulmon Dis. 2019:14:2409-21.

61. Oh YM, Lee KS, Hong Y, et al. Blood eosinophil count as a prognostic biomarker in COPD. Int I Chron Obstruct Pulmon Dis. 2018;13:3589-96

62. Oshagbemi OA, Franssen FME, van Kraaij S, et al. Blood eosinophil counts, withdrawal of inhaled corticosteroids and risk of COPD exacerbations and mortality in the clinical practice research datalink (CPRD). COPD. 2019;16:152-9.

63. Marin Trigo JM, Martinez M, Cubero P, et al. Blood eosinophils and outcomes in COPD. Eur Respir J. 2016:48(Suppl.60):PA4624

64. Pavord ID, Lettis S, Anzueto A, Barnes N. Blood eosinophil count and pneumonia risk in patients with chronic obstructive pulmonary disease: a patient-level meta-analysis. Lancet Respir Med. 2016:4:731-41.

65. Martinez-Garcia MA, Faner R, Oscullo G, et al. Inhaled steroids, circulating eosinophils, chronic airway infection, and pneumonia risk in chronic obstructive pulmonary disease. A network analysis. Am I Respir Crit Care Med. 2020;201:1078-85.

66. Vedel-Krogh S, Nordestgaard BG, Lange P, et al. Blood eosinophil count and risk of pneumonia hospitalisations in individuals with COPD Eur Respir I. 2018:51:1800120.

67. Pascoe S, Locantore N, Dransfield MT, et al. Blood eosinophil counts, exacerbations, and response to the addition of inhaled fluticasone furoate to vilanterol in patients with chronic obstructive pulmonary disease: a secondary analysis of data from two parallel randomised controlled trials. Lancet Respir Med. 2015;3:435-42

68. Tinè $\mathrm{M}$, Biondini $\mathrm{D}$, Semenzato $\mathrm{U}$, et al. Reassessing the role of eosinophils as a biomarker in chronic obstructive pulmonary disease. J Clin Med. 2019;8:962

69. Bafadhel M, Peterson S, De Blas MA, et al. Predictors of exacerbation risk and response to budesonide in patients with chronic obstructive pulmonary disease: a post-hoc analysis of three randomised trials. Lancet Respir Med. 2018;6:117-26.

70. Bafadhel M, Singh D, Jenkins C, et al. Reduced risk of clinically important deteriorations by ICS in COPD is eosinophil dependent: a pooled post-hoc analysis. Respir Res. 2020;21:17.

71. Cazzola M, Rogliani P, Calzetta L, Matera MG. Triple therapy versus single and dual long-acting bronchodilator therapy in COPD: a systematic review and meta-analysis. Eur Respir J. 2018;52:1801586.

72. Cheng SL. Blood eosinophils and inhaled corticosteroids in patients with COPD: systematic review and meta-analysis. Int J Chron Obstruct Pulmon Dis. 2018;13:2775-84.

73. Watz H, Tetzlaff K, Wouters EF, et al. Blood eosinophil count and exacerbations in severe chronic obstructive pulmonary disease after withdrawal of inhaled corticosteroids: a post-hoc analysis of the WISDOM trial. Lancet Respir Med. 2016;4:390-8.

74. Calverley PMA, Tetzlaff K, Vogelmeier C, et al. Eosinophilia, frequent exacerbations, and steroid response in chronic obstructive pulmonary disease. Am I Respir Crit Care Med. 2017;196:1219-21

75. Wedzicha JA, Banerji D, Chapman KR, et al. Indacaterolglycopyrronium versus salmeterol-fluticasone for COPD. N Eng J Med. 2016;374:2222-34

76. Roche N, Chapman KR, Vogelmeier CF, et al. Blood eosinophils and response to maintenance chronic obstructive pulmonary disease treatment. Data from the FLAME trial. Am J Respir Crit Care Med. 2017;195:1189-97.

77. Harries TH, Rowland V, Corrigan CJ, et al. Blood eosinophil count, a marker of inhaled corticosteroid effectiveness in preventing COPD exacerbations in post-hoc RCT and observational studies: systematic review and meta-analysis. Respir Res. 2020;21:3.

78. Iqbal A, Barnes NC, Brooks J. Is blood eosinophil count a predictor of response to bronchodilators in chronic obstructive pulmonary disease? Results from post hoc subgroup analyses. Clin Drug Investig. 2015;35:685-8.

79. Bafadhel M, Barnes N, Bourke S, et al. Analysis of IMPACT: is one blood eosinophil count measurement sufficient to predict ICS treatment response in COPD? Eur Respir J. 2019;52:OA260.

80. Mathioudakis AG, Bikov A, Foden P, et al. Change in blood eosinophils following treatment with inhaled corticosteroids may predict long-term clinical response in COPD. Eur Respir 2020;55:1902119.

81. Singh $\mathrm{D}$, Bafadhel $M$, Brightling $C E$, et al. Blood eosinophil counts in clinical trials for chronic obstructive pulmonar disease. Am J Respir Crit Care Med. 2020;202:660-71.

82. Criner GJ. Rebuttal from Dr Criner. Chest. 2020;157:1079-80.

83. Criner GJ, Celli BR, Singh D, et al. Predicting response to benralizumab in chronic obstructive pulmonary disease: analyses of GALATHEA and TERRANOVA studies. Lancet Respir Med. 2020:8:158-70.

84. Cazzola M, Rogliani P, Novelli L, Matera MG. Inhaled corticosteroids for chronic obstructive pulmonary disease Expert Opin Pharmacother. 2013;14:2489-99.

85. Papaioannou Al, Kostikas K, Papaporfyriou A, et al. Emphysematous phenotype is characterized by low blood eosinophils: a cross-sectional study. COPD. 2017;14:635-40.

86. Landis SH, Pimenta JM, Yang S, et al. Association between blood eosinophils and acute exacerbation of COPD risk in patients with COPD in primary care. Respir Med X. 2019;1:100011

87. Rampon G, Reddy M, Burke S, et al. Prescription tendencies and clinical outcomes of ICS for management of COPD, A 'real world' review. Abstr. Am J Respir Critical Care Med. 2020;201:A3353.

88. Pavord ID. Blood Eosinophil-directed management of airway disease: the past, present and future. Am I Respir Crit Care Med. 2020;202:637-9. 